\title{
Enhanced escape of non-esterified fatty acids from tissue uptake: its role in impaired insulin-induced lowering of total rate of appearance in obesity and Type II diabetes mellitus
}

\author{
S. C. Riemens, W.J.Sluiter, R.P. F. Dullaart \\ Department of Endocrinology, University Hospital Groningen, The Netherlands
}

\begin{abstract}
Aims/hypothesis. To estimate non-esterified fatty acids kinetics in patients with Type II (non-insulin-dependent) diabetes mellitus and obese subjects in the postabsorptive state and during hyperinsulinaemia using non-equlibrium tracer conditions.

Methods. We evaluated the effect of hyperinsulinaemia [euglycaemic clamp with insulin infused at $30 \mathrm{mU} \cdot \mathrm{kg}^{-1} \cdot \mathrm{h}^{-1} \quad(3-4 \mathrm{~h})$ and $150 \mathrm{mU} \cdot \mathrm{kg}^{-1} \cdot \mathrm{h}^{-1}$ $(3 \mathrm{~h})]$ on non-esterified fatty acid kinetics, traced with $\left[{ }^{14} \mathrm{C}\right]$-palmitate using non-equlibrium tracer conditions in non-obese and obese healthy subjects and Type II diabetic patients (10 per group). MichaelisMenten kinetics were applied for total non-esterified fatty acid disposal, which was assumed to be composed of total arterial plasma non-esterified fatty acid rate of appearance (equalling the rate of disappearance) and tissue uptake of non-esterified fatty acids derived from intravascular triglyceride hydrolysis. A model was developed to calculate the rate of escape of non-esterified fatty acids from tissue uptake and the net rate of tissue lipolysis.

Results. Total arterial plasma non-esterified fatty acid rate of appearance was lower in non-obese healthy subjects than in the other groups at low insulin infu-
\end{abstract}

sion $(p<0.05)$ and in obese Type II diabetic patients at high insulin infusion $(p<0.05)$. Plasma triglycerides were also lowest in non-obese healthy subjects during hyperinsulinaemia $(p<0.05$ from other groups). The rate of escape from tissue uptake decreased during hyperinsulinaemia $(p<0.05$ for each group) but remained higher in obese Type II diabetic patients ( $p<0.05$ from non-obese healthy subjects). In contrast, net rate of tissue lipolysis was not different between the groups at baseline and its decline during hyperinsulinaemia ( $p<0.05$ for each group) was similar in all groups.

Conclusion/interpretation. This study challenges the view that the antilipolytic effect of insulin is impaired in Type II diabetes and obesity. We suggest that a high plasma triglyceride concentration causes a higher escape of non-esterified fatty acids from tissue uptake, leading to an impaired suppression of total arterial plasma rate of appearance during a low degree of hyperinsulinaemia in obese subjects and Type II diabetic patients and during a high degree of hyperinsulinaemia in obese Type II diabetic patients. [Diabetologia (2000) 43: 416-426]

Keywords Non-esterified fatty acids, insulin, Type II diabetes mellitus, obesity, lipolysis, triglycerides.
Received: 4 October 1999 and in revised form: 14 December 1999

Corresponding author: R.P.F. Dullaart, MD, PhD, Department of Endocrinology, State University Hospital Groningen, PO Box 30.001, 9700 RB Groningen, The Netherlands

Abbreviations: TBD, Total body NEFA disposal; ESC, rate of escape of NEFA from tissue uptake; Ext, extraction coefficient; RL, net rate of tissue lipolysis; $T R_{a}$, total arterial plasma
NEFA rate of appearance; LPL, lipoprotein lipase; HL, hepatic lipase; apo, apolipoprotein; $V_{d}$, distribution volume; $k$, fractional removal constant; MCR, metabolic clearance rate; $V$, rate of disposal; $V_{m}$, maximum transport capacity; $\mathrm{S}$, actual NEFA concentration at the site of transport; $K_{m}$, NEFA concentration at the site of transport at half maximum disposal rate; $A$, reaction rate constant of intravascular triglyceride hydrolysis; TU, tissue uptake; $B, V_{m} / V_{d} ; \mathrm{PF}$, plasma flow. 
Non-esterified fatty acids (NEFA) are important substrates for hepatic triglyceride synthesis [1]. Furthermore, NEFA could compete with glucose for substrate oxidation as originally postulated [2] or, as shown more recently, impair glucose uptake in muscle by inhibition of glucose transport or phosphorylation [3]. Increased plasma NEFA (and glycerol) concentrations could also impair suppression of hepatic glucose production by insulin [4, 5]. Increased NEFA availability is, therefore, thought to play an important part in the pathogenesis of hypertriglyceridaemia and insulin resistance of glucose metabolism as observed in Type II (non-insulin-dependent) diabetes mellitus and obesity $[1,6,7]$.

Insulin efficiently lowers plasma NEFA, which is predominantly due to its antilipolytic action by inhibiting hormone-sensitive lipase in adipose tissue [1]. Several $[8-10]$, but not all $[11,12]$ in vitro studies have shown that the antilipolytic action of insulin is unimpaired in adipose tissue from patients with Type II diabetes and obese subjects. Using prolonged infusion of radiolabelled palmitate to trace plasma NEFA and applying equilibrium tracer conditions, it has been documented that the effect of insulin to maximally suppress the rate of appearance of plasma NEFA is impaired in Type II diabetes [13,14]. In obesity, the postabsorptive rate of appearance of plasma NEFA could be increased as a consequence of the enlarged fat mass, whereas maximum responsiveness to insulin is unaltered $[13,15,16]$. In these studies [13-16], the rate of appearance of NEFA was considered to reflect influx of NEFA derived from adipose tissue lipolysis and hence a blunted suppression of NEFA influx by insulin was taken as evidence in support of impaired antilipolysis by insulin in vivo. This assumption may, however, need some modification. Firstly, NEFA derived from lipoprotein lipase (LPL)-mediated intravascular triglyceride hydrolysis is now recognised to escape in part from extraction by peripheral, e.g. adipose, tissues both in the postabsorptive and in the postprandial state [17-19], thus contributing to NEFA influx. Secondly, plasma NEFA are quickly re-esterified to triglyceride by the liver [20-22]. Together this will lead to underestimation of the rate of appearance of NEFA with prolonged radiolabel infusion in the basal state, because of recirculation of label derived from intravascular hydrolysis of radiolabelled triglyceride [22]. We have recently developed and validated a method to measure NEFA kinetics during non-equilibrium tracer conditions with short-term $\left[{ }^{14} \mathrm{C}\right]$-palmitate infusion, thereby avoiding the effect of label recirculation on the measurement of NEFA rate of appearance [22]. In the present study, this method was used to document the effect of insulin on NEFA kinetic variables in non-obese and obese healthy subjects and patients with Type II diabetes. Furthermore, a model is provided to estimate the contributions of the net rate of lipolysis and of the rate of appearance of NEFA that escape from tissue uptake after intravascular release to total arterial plasma rate of appearance during postabsorptive and hyperinsulinaemic circumstances.

\section{Subjects and methods}

Subjects. The protocol was approved by the local medical ethics committee. Written informed consent was obtained from all participants. Smokers were excluded. Type II diabetes was diagnosed according to National Diabetes Group Criteria [23] and age at onset was over 40 years in the patients with Type II diabetes. None of the diabetic patients had suffered from ketoacidotic periods or was treated with insulin. In the non-diabetic subjects, diabetes was excluded by a 75-g oral glucose tolerance test with a fasting venous blood glucose less than $6.7 \mathrm{mmol} / \mathrm{l}$ and 2-h blood glucose concentration less than $7.8 \mathrm{mmol} / \mathrm{l}$ as cut-off values. Excluded were subjects with a fasting plasma cholesterol higher than $8.0 \mathrm{mmol} / \mathrm{l}$ or triglyceride concentration above $4.5 \mathrm{mmol} / \mathrm{l}$ or both, hypertension (systolic blood pressure $>160 \mathrm{mmHg}$ or diastolic blood pressure $>95 \mathrm{mmHg}$ or both), macroproteinuria (> $500 \mathrm{mg} /$ day) and microalbuminuria (overnight urinary albumin excretion rate $>20 \mu \mathrm{g} / \mathrm{min}$ ), clinically manifest cardiovascular disease and a family history of hyperlipidaemia or premature cardiovascular disease. The thyreotropin concentration, liver function tests and serum creatinine concentration were within the normal range. Alcohol intake was three or less consumptions a day. No medication other than sulphonylurea and metformin was allowed. Body mass index (BMI) was calculated as weight $(\mathrm{kg})$ divided by height $\left(\mathrm{m}^{2}\right)$. Obesity was defined as BMI exceeding $27 \mathrm{~kg} / \mathrm{m}^{2}$. To assess body composition bioelectrical impedance analysis (BIA) was used with a tetrapolar BIA-101 analyser (RJL Systems, Detroit, Mich., USA). After application of an alternating electrical current of $800 \mu \mathrm{A}$ at $50 \mathrm{kHz}$, resistance and reactance were assessed [24]. Fat-free mass was estimated by using the equation supplied by the manufacturer. Body fat was calculated by subtracting fat-free mass from body weight.

The participants were ten non-obese healthy subjects, ten obese healthy subjects, ten non-obese patients with Type II diabetes and ten obese patients with Type II diabetes. They were individually matched for age (within 5 years). Patients with Type II diabetes were matched for diabetes duration (within 5 years). Most of the subjects also participated in another study that aimed to evaluate the effect of hyperinsulinaemia on plasma lipid transfer proteins [25].

Procedure. The subjects adhered to their habitual diet and the Type II diabetic patients continued their blood glucose lowering drugs until the study day. They refrained from drinking alcohol on the day before the study and were kept fasting after 20.00 hours. On the study day they remained supine from 8.00 hours onwards. One hand vein was cannulated and the canula was kept patent with a $\mathrm{NaCl}$ drip $(154 \mathrm{mmol} / \mathrm{l}, 30 \mathrm{ml} /$ h). This hand was placed in a thermoregulated box with an ambient temperature of $55^{\circ} \mathrm{C}$ to obtain arterialised venous blood. This procedure is a suitable alternative to arterial blood sampling for NEFA tracer studies [26]. Two forearm veins of the contralateral arm were cannulated for infusion of dextrose, insulin and $\left[1-{ }^{14} \mathrm{C}\right]$-palmitate. Non-esterified fatty acid kinetic variables were obtained by infusion of $\left[1-{ }^{14} \mathrm{C}\right]$-palmitate as a tracer using non-equilibrium tracer conditions as described recently [22]. In brief, $\left[1-{ }^{14} \mathrm{C}\right]$-palmitate (approximately $0.2 \mu \mathrm{Ci}$ / $\mathrm{min}$, equivalent to $7.5 \mathrm{kBq} / \mathrm{min}$ ) was infused for $10 \mathrm{~min}$ at baseline after $1 \mathrm{~h}$ of supine rest and at the end of the two insulin in- 
fusion steps (see below). During each of the three tracer infusion periods blood samples were taken at the start of the infusion and at 2-min intervals thereafter for $20 \mathrm{~min}$. In this manner NEFA kinetic variables were calculated at the upstroke (0-10 $\mathrm{min})$ and downstroke (10-20 $\mathrm{min})$ of the plasma palmitate specific activity curve and the result of the upstroke and downstroke measurements were averaged. By this method the radiation dose is limited to $0.16 \mathrm{mSv}$ per measurement. After the baseline period, a two-step hyperinsulinaemic euglycaemic clamp was carried out with insulin infused at a rate of $30 \mathrm{mU} \cdot \mathrm{kg}^{-1} \cdot \mathrm{h}^{-1}$ for $3 \mathrm{~h}(4 \mathrm{~h}$ in Type II diabetic patients to gradually lower blood glucose to target concentrations), followed by an infusion rate of $150 \mathrm{mU} \cdot \mathrm{kg}^{-1} \cdot \mathrm{h}^{-1}$ for $3 \mathrm{~h}$. An insulin bolus of $5 \mathrm{mU} / \mathrm{kg}$ was given directly before the insulin infusions. Blood glucose was kept at approximately $0.6 \mathrm{mmol} / \mathrm{l}$ below fasting concentrations in non-diabetic subjects. Target blood glucose concentration was $4.4 \mathrm{mmol} / \mathrm{l}$ in Type II diabetic patients. Blood glucose was measured at intervals of 5-10 min. Blood glucose concentration was allowed to decline initially and then maintained at these targets by a variable dextrose infusion $(20 \% \mathrm{w} / \mathrm{w})$ to which $\mathrm{KCl}$ was added to prevent hypokalaemia. The mean glucose infusion rate (in $\mathrm{mmol} \cdot \mathrm{m}^{-2} \cdot \mathrm{min}^{-1}$ ) during the last hour of each insulin step was used to estimate exogenous glucose disposal. Additional blood samples for measurement of plasma triglycerides and insulin were taken at baseline and at the end of each insulin step. Plasma was obtained $20 \mathrm{~min}$ after intravenous injection of $50 \mathrm{U} / \mathrm{kg}$ of heparin for lipoprotein lipase (LPL) and hepatic lipase (HL) measurement 1-2 weeks before the study. This was done to avoid on effect of heparin treatment on triglyceride and NEFA metabolism during the experiments.

Laboratory methods. The $\left[1-{ }^{14} \mathrm{C}\right]$-palmitate [specific activity, 1.85-2.29 GBq/mmol (CFA23, Amersham, UK)] was prepared for intravenous infusion as described [22]. Radiochemical purity was well over $95 \%$. Blood was collected into EDTA $(1.5 \mathrm{mg} / \mathrm{ml})$ containing tubes and was placed immediately on ice. Plasma was obtained within $30 \mathrm{~min}$ by centrifugation at $3000 \mathrm{rpm}$ for $15 \mathrm{~min}$ at $4^{\circ} \mathrm{C}$. Samples were frozen immediately at $-70^{\circ} \mathrm{C}$ until analysis. Plasma NEFA were measured using a kit from Wako Chemicals (Neuss, Germany; catalogue no. 994-75409). Radioactivity was counted after extraction of NEFA with a mixture of chloroform and heptane (CHM, 1:1, $\mathrm{v} / \mathrm{v})$ to which methanol was added $(98: 2, \mathrm{v} / \mathrm{v})$ [22]. Co-extraction of triglyceride was prevented by addition of $1.0 \mathrm{ml}$ of $35 \mathrm{mmol} / \mathrm{l}$ phosphate buffer $(\mathrm{pH} 6.4)$ to $0.2 \mathrm{ml}$ of the samples before extraction with CHM. No internal standard was used to monitor recovery of NEFA, which is virtually complete. A 5 -ml aliquot of duplicate samples of the organic phases was combined in a counting vial, dried at $37^{\circ} \mathrm{C}$ under nitrogen stream and counted after addition of scintillation fluid, with a counting error below $1 \%$.

Lipoprotein lipase and HL activities were assayed as described [27]. Lipids were measured in plasma and in the high density lipoprotein (HDL)-containing supernatant fraction after removal of apolipoprotein (apo) B-containing lipoproteins with polyethylene glycol-6000 [28]. Plasma cholesterol and triglycerides were measured using enzymatic methods. Apo B was assayed by immunoturbidimetry (Boehringer Mannheim, Mannheim, Germany, catalogue no. 726494). Blood glucose was measured with a Yellow Springs Glucose Analyser (model 23A, Yellow Springs, Yellow Springs, Ohio, USA). Glycated haemoglobin $\left(\mathrm{HbA}_{1 \mathrm{c}}\right)$ was measured by high performance liquid chromatography (Bio-Rad, Veenendaal, The Netherlands, reference range 4.6-6.1\%). Plasma-free insulin was assayed by radioimmunoassay (Novo Nordisk Immunochemical Department, Copenhagen, Denmark).
Calculations of NEFA kinetic variables. The following NEFA kinetic variables were calculated: plasma NEFA concentration, total rate of appearance $\left(T R_{a}\right.$, in $\left.\mu \mathrm{mol} \cdot \mathrm{min}^{-1} \cdot \mathrm{m}^{-2}\right)$, distribution volume $\left(V_{d}\right.$, in $\left.1 / \mathrm{m}^{2}\right)$, fractional removal constant $(k$, in $\%$ per min) and metabolic clearance rate (MCR, in $\mathrm{ml} \cdot \mathrm{min}^{-1} \cdot \mathrm{m}^{-2}$ ), where $\mathrm{MCR}=k \cdot V_{d}$. Because of the extremely short half life of plasma NEFA [22, 29], it is preferable to interpret $V_{d}$ in terms of a volume flow, making $\mathrm{k}$ an extraction coefficient. The mathematics used to calculate these NEFA kinetics variables have been described elsewhere [22]. The within-day coefficients of variation (CVs) of plasma NEFA, $T R_{a}, V_{d}, k$ and MCR using this method are $5.1 \%$, $5.8 \%, 6.8 \%, 12.6 \%$ and $8.2 \%$, respectively.

The amount of intravascularly released NEFA from triglyceride hydrolysis that escapes from tissue uptake was estimated assuming that at physiological concentrations NEFA disposal into tissues is a facilitated process that follows Michaelis-Menten kinetics [30-33]. The rate of whole-body total NEFA disposal (TBD), is thus equivalent to $V=\frac{V_{m} \cdot[\mathrm{S}]}{[\mathrm{S}]+K_{m}}$. This means that the rate of disposal $(V)$ is governed by the maximum transport capacity $\left(V_{m}\right)$, the actual NEFA concentration at the site of transport (S) and that at the site of transport at half maximum disposal rate $\left(K_{m}\right)$. The actual NEFA concentration at the site of transport is composed of the measured arterial plasma NEFA concentration and the NEFA released intravascularly from triglyceride hydrolysis by LPL: $\mathrm{S}=$ plasma $\mathrm{NEFA}+A \cdot \mathrm{LPL} \cdot$ plasma triglyceride, where $A$ represents the reaction rate constant of intravascular triglyceride hydrolysis. Thus TBD has two components because of the two sources of NEFA that make up S:

1. the rate of disposal of arterial plasma NEFA, amounting to $V_{m} \cdot$ plasma NEFA $/\left([\mathrm{S}]+K_{m}\right)$ and

2. the rate of disposal of intravascularly released NEFA (tissue uptake, TU), amounting to $V_{m} \cdot A \cdot \mathrm{LPL} \cdot$ plasma triglyceride/ $\left([\mathrm{S}]+K_{m}\right)$.

In this study, arterial plasma NEFA disposal was measured as $T R_{a}$, assuming that this rate of appearance equals the rate of disappearance during all kinetic experiments [13-16]. This results in equation 1: $T R_{a}=\mathrm{MCR} \cdot$ plasma $\mathrm{NEFA}=V_{m} \cdot$ plasma $\mathrm{NEFA} /\left([\mathrm{S}]+K_{m}\right)$. Rearrangement of equation 1 results in equation 2: $1 / \mathrm{MCR}=\left([\mathrm{S}]+K_{m}\right) / V_{m}=($ plasma $\mathrm{NEFA}+A$. LPL - plasma triglyceride $\left.+K_{m}\right) / V_{m}$. The $V_{m}$ is dependent on the plasma flow (PF) through tissues capable of NEFA uptake (PF). Plasma flow can be expressed as a fraction of $V_{d}$. Thus, $V_{m}$ was expressed in relation to $V_{d}$, giving equation 3: $1 / \mathrm{MCR}=$ (plasma $\mathrm{NEFA}+A \cdot \mathrm{LPL} \cdot$ plasma triglyceride + $\left.K_{m}\right) /\left(B \cdot V_{d}\right)$, where $B$ represents $V_{m} / V_{d}$. Using multiple regression analysis with $1 / \mathrm{MCR}$ as a dependent variable and plasma $\mathrm{NEFA} / V_{d}$ and the product of LPL and plasma triglyceride/ $V_{d}$ as independent variables the mean values of $B, K_{m}$ and $A$ can be disclosed. Further, we evaluated whether obesity, the diabetic state and the plasma insulin concentration statistically significantly influenced the values of $B, K_{m}$ and $A$ in this multiple regression analysis. It should be noted that $B \cdot V_{d} / K_{m}$ is the theoretical maximum MCR at $\mathrm{S}=0$. In this situation, extraction is $100 \%$ and $B \cdot V_{d} / K_{m}$ equals PF through tissues that are capable of NEFA uptake.

With the use of the calculated mean $A$ of the whole group, S can be approximated for each subject during the three kinetic experiments as $\mathrm{S}=$ plasma $\mathrm{NEFA}+A \cdot \mathrm{LPL} \cdot$ plasma triglyceride. Using the group means of $A, B$ and $K_{m}$ the concomitant rate of intravascular release of NEFA is approximated as $A \cdot \mathrm{LPL} \cdot$ plasma triglyceride $\cdot B \cdot V_{d} / K_{m}$ of which only a part is taken up directly by tissue: TU $=A \cdot \mathrm{LPL} \cdot$ plasma triglycer- 
Table 1. Clinical characteristics, blood glucose, plasma insulin and glucose infusion rates in non-obese and obese healthy subjects and patients with Type II diabetes

\begin{tabular}{|c|c|c|c|c|}
\hline \multirow{2}{*}{$\begin{array}{l}\text { BMI groups } \\
n\end{array}$} & \multicolumn{2}{|l|}{ Healthy subjects } & \multicolumn{2}{|c|}{$\underline{\text { Patients with Type II diabetes }}$} \\
\hline & $\begin{array}{l}<27 \mathrm{~kg} / \mathrm{m}^{2} \\
10\end{array}$ & $\begin{array}{l}>27 \mathrm{~kg} / \mathrm{m}^{2} \\
10\end{array}$ & $\begin{array}{l}<27 \mathrm{~kg} / \mathrm{m}^{2} \\
10\end{array}$ & $\begin{array}{l}>27 \mathrm{~kg} / \mathrm{m}^{2} \\
10\end{array}$ \\
\hline $\begin{array}{l}\text { Age (years) } \\
\text { Diabetes duration (years) } \\
\operatorname{HbA}_{1 \mathrm{c}}(\%) \\
\mathrm{BMI}\left(\mathrm{kg} / \mathrm{m}^{2}\right) \\
\text { Fat mass }(\mathrm{kg})\end{array}$ & $\begin{array}{l}51(44-60) \\
- \\
5.3(5.0-5.7) \\
23.7(21.6-25.5) \\
12(9-19)\end{array}$ & $\begin{array}{l}55(53-58) \\
- \\
5.5(5.4-5.8)^{\mathrm{b}} \\
28.9(28.3-29.7)^{\mathrm{a}} \\
24(19-28)^{\mathrm{a}}\end{array}$ & $\begin{array}{l}55(44-60) \\
3(1-16) \\
7.0(6.4-8.2)^{\mathrm{a}} \\
25.3(23.3-25.7)^{\mathrm{b}} \\
15(14-17)^{\mathrm{b}}\end{array}$ & $\begin{array}{l}56(53-60) \\
4(3-8) \\
7.0(6.4-7.9)^{\mathrm{a}} \\
29.8(28.1-36.8)^{\mathrm{a}} \\
22(17-28)^{\mathrm{a}}\end{array}$ \\
\hline $\begin{array}{l}\text { Blood glucose }(\mathrm{mmol} / \mathrm{l}) \\
\text { baseline } \\
1^{0} \text { step } \\
2^{0} \text { step }\end{array}$ & $\begin{array}{l}5.1(4.5-5.3) \\
4.5(4.4-5.0)^{\mathrm{c}} \\
4.8(4.2-5.0)^{\mathrm{c}}\end{array}$ & $\begin{array}{l}5.4(5.0-5.7) \\
4.7(4.1-4.9)^{\mathrm{c}} \\
5.0(4.6-5.1)^{\mathrm{c}}\end{array}$ & $\begin{array}{l}8.0(7.0-9.0)^{\mathrm{a}} \\
4.4(4.3-4.6)^{\mathrm{c}} \\
4.4(4.4-4.5)^{\mathrm{c}}\end{array}$ & $\begin{array}{l}8.2(7.0-9.9)^{\mathrm{a}} \\
4.5(4.3-5.1)^{\mathrm{c}} \\
4.6(4.5-4.8)^{\mathrm{c}}\end{array}$ \\
\hline $\begin{array}{l}\text { Plasma insulin }(\mathrm{mU} / \mathrm{l}) \\
\text { baseline } \\
1^{0} \text { step } \\
2^{0} \text { step }\end{array}$ & $\begin{array}{l}10(9-11) \\
28(25-30)^{\mathrm{c}} \\
139(121-166)^{\mathrm{c}}\end{array}$ & $\begin{array}{l}15(10-20) \\
35(29-54)^{\mathrm{c}} \\
214(157-278)^{\mathrm{a}, \mathrm{c}}\end{array}$ & $\begin{array}{l}10(6-15) \\
31(28-47)^{\mathrm{c}} \\
166(131-187)^{\mathrm{c}}\end{array}$ & $\begin{array}{l}15(11-19) \\
36(33-49)^{\mathrm{c}} \\
194(175-229)^{\mathrm{a}, \mathrm{c}}\end{array}$ \\
\hline $\begin{array}{l}\text { Glucose infusion rate }(\mathrm{mmc} \\
1^{0} \text { step } \\
2^{0} \text { step }\end{array}$ & $\begin{array}{l}\left.\mathrm{m}^{-2}\right) \\
1.47(1.20-2.27) \\
3.34(2.49-3.84)^{\mathrm{d}}\end{array}$ & $\begin{array}{l}0.97(0.62-1.15)^{\mathrm{a}, \mathrm{b}} \\
2.74(2.54-3.12)^{\mathrm{b}, \mathrm{d}}\end{array}$ & $\begin{array}{l}0.79(0.33-1.05)^{\mathrm{a}} \\
2.27(1.37-2.60)^{\mathrm{a}, \mathrm{d}}\end{array}$ & $\begin{array}{l}0.22(0.16-0.44)^{\mathrm{a}} \\
1.42(1.10-1.96)^{\mathrm{a}, \mathrm{d}}\end{array}$ \\
\hline
\end{tabular}

Data in medians (interquartile ranges). Plasma insulin concentrations at baseline and at the end of each insulin infusion step, blood glucose and glucose infusion rates at the last hour of each insulin infusion step are given. ${ }^{\mathrm{a}} p<0.05$ from non-obese healthy subjects; ${ }^{\mathrm{b}} p<0.05$ from obese patients with Type II diabetes; ${ }^{\mathrm{c}} p<0.05$ from baseline; ${ }^{\mathrm{d}} p<0.05$ from first insulin infusion step ide $\cdot B \cdot V_{d} /\left([\mathrm{S}]+K_{m}\right)$. As a consequence, the concomitant coefficient of extraction (Ext) amounts to $K_{m} /\left([\mathrm{S}]+K_{m}\right)$. The part of the NEFA that originates from intravascular triglyceride hydrolysis, which escapes from direct uptake by tissue (ESC) will appear in the circulation and will approximate $\mathrm{ESC}=(1-\mathrm{Ext}) \cdot A \cdot \mathrm{LPL} \cdot$ plasma triglyceride $\cdot B \cdot V_{d}$. If this part ESC is subtracted from the total rate of appearance $T R_{a}$, an estimate of the net rate of tissue lipolysis (RL) is obtained. Finally, as both $T R_{a}$ and TU are known, TBD can be calculated as $\mathrm{TBD}=T R_{a}+\mathrm{TU}$.

Statistical analysis. Because of non-parametric distribution of variables, data are given in medians (interquartile ranges) unless stated otherwise. Between group comparisons of variables was carried out by Kruskal-Wallis analysis of variance. Within group changes in variables were evaluated by Friedman's two-way analysis of variance. Duncan's method was applied to correct for multiple comparisons. Multiple regression analysis was used to evaluate the independent relations between variables. A two-sided $p$ value less than 0.05 was taken as significant.

\section{Results}

Age was similar in the groups and diabetes duration was not different between non-obese and obese patients with Type II diabetes (Table 1). Haemoglobin $\mathrm{A}_{1 \mathrm{c}}$ was higher in the diabetic than in the non-diabetic groups. Of the non-obese diabetic patients, two were treated with diet alone, four with diet plus sulphonylurea and four received sulphonylurea in combination with metformin. In addition to diet, four of the obese diabetic patients were treated with sulpho- nylurea, five received sulphonylurea in combination with metformin and one patient was medically treated with metformin. Body mass index and fat mass were similarly higher in the obese healthy and obese subjects with Type II diabetes than in the non-obese groups (Table 1). Blood glucose was higher in diabetic patients at baseline but during the clamp no between-group differences in blood glucose were present (Table 1). In the combined subjects, the CV of blood glucose during high-dose insulin infusion was $6.4 \pm 3.4 \%$. Plasma insulin was not statistically significantly different between the groups at baseline. During the second insulin infusion step plasma insulin was higher in obese healthy subjects and in obese patients with Type II diabetes than in lean healthy subjects. (Table 1). Glucose infusion rate was highest in non-obese healthy subjects and lowest in obese Type II diabetic patients (Table 1).

Plasma total cholesterol was not different between the groups but HDL cholesterol was lowest in obese Type II diabetic patients and highest in non-obese healthy subjects (Table 2). Plasma apo-B was higher in the diabetic groups than in non-obese healthy subjects. Lipoprotein lipase activity in post-heparin plasma was not significantly different between the groups but HL activity was higher in obese healthy and obese Type II diabetic subjects than in non-obese healthy subjects (Table 2). Baseline plasma triglyceride was lowest in non-obese healthy subjects and highest in obese Type II diabetic patients (Table 2). During the second insulin infusion step plasma triglyceride decreased but its change was not statistically 
Table 2. Baseline plasma lipid variables, lipoprotein lipase (LPL) and hepatic lipase (HL) activities in post-heparin plasma as well as plasma triglycerides at baseline and during hyper- insulinaemia in non-obese and obese healthy subjects and patients with Type II diabetes

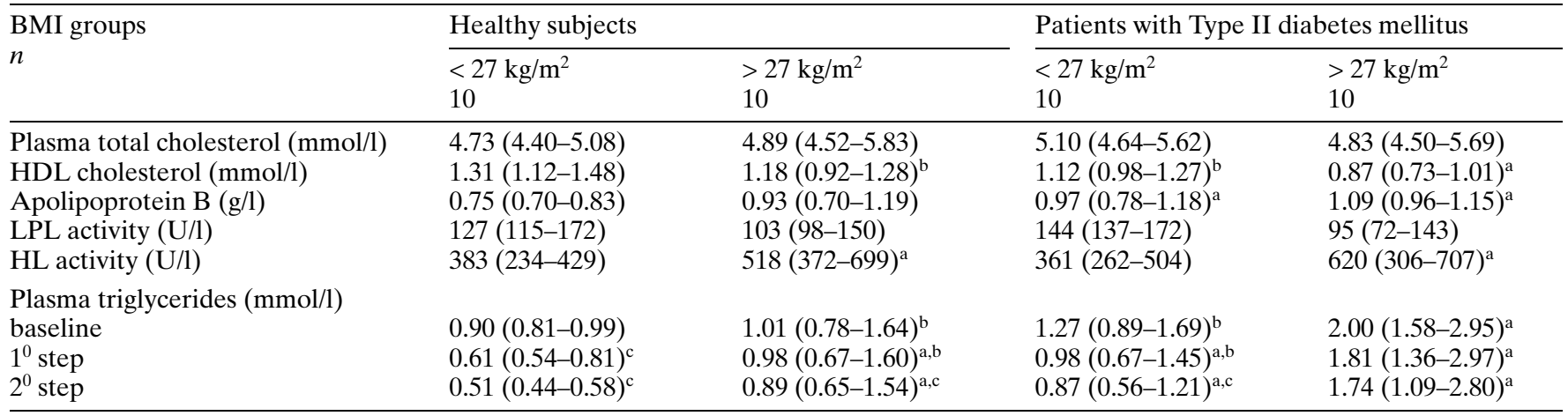

Data in medians (interquartile ranges). ${ }^{\mathrm{a}} p<0.05$ from non-obese healthy subjects; ${ }^{\mathrm{b}} p<0.05$ from obese patients with Type II diabetes; ${ }^{\mathrm{c}} p<0.05$ from baseline

Table 3. Non-esterified fatty acid (NEFA) kinetic variables at baseline and during hyperinsulinaemia in non-obese and obese healthy subjects and patients with Type II diabetes

\begin{tabular}{|c|c|c|c|c|}
\hline \multirow{2}{*}{$\begin{array}{l}\text { BMI groups } \\
n\end{array}$} & \multicolumn{2}{|l|}{ Healthy subjects } & \multicolumn{2}{|c|}{ Patients with Type II diabetes } \\
\hline & $\begin{array}{l}<27 \mathrm{~kg} / \mathrm{m}^{2} \\
10\end{array}$ & $\begin{array}{l}>27 \mathrm{~kg} / \mathrm{m}^{2} \\
10\end{array}$ & $\begin{array}{l}<27 \mathrm{~kg} / \mathrm{m}^{2} \\
10\end{array}$ & $\begin{array}{l}>27 \mathrm{~kg} / \mathrm{m}^{2} \\
10\end{array}$ \\
\hline $\begin{array}{l}\mathrm{k}(\% / \mathrm{min})^{\mathrm{b}} \\
\text { baseline } \\
1^{0} \text { step } \\
2^{0} \text { step }\end{array}$ & $\begin{array}{l}27(24-31) \\
36(30-40) \\
38(32-53)^{\mathrm{g}}\end{array}$ & $\begin{array}{l}26(23-34) \\
42(32-47) \\
51(45-63)^{f, g}\end{array}$ & $\begin{array}{l}26(23-29) \\
34(30-50) \\
39(34-47)^{\mathrm{g}}\end{array}$ & $\begin{array}{l}24(18-43) \\
31(23-36) \\
31(29-36)\end{array}$ \\
\hline $\begin{array}{l}\mathrm{TR}_{\mathrm{a}}\left(\mu \mathrm{mol} \cdot \mathrm{min}^{-1} \cdot \mathrm{m}^{-2}\right)^{\mathrm{d}} \\
\text { baseline } \\
1^{0} \text { step } \\
2^{0} \text { step }\end{array}$ & $\begin{array}{l}219(186-326) \\
29(15-39)^{\mathrm{g}} \\
12(10-26)^{\mathrm{g}}\end{array}$ & $\begin{array}{l}253(198-297) \\
53(39-58)^{\mathrm{e}, \mathrm{g}} \\
39(29-55)^{\mathrm{g}}\end{array}$ & $\begin{array}{l}305(242-447) \\
74(39-227)^{\mathrm{e}, \mathrm{g}} \\
31(11-71)^{\mathrm{g}}\end{array}$ & $\begin{array}{l}357(218-633) \\
86(72-113)^{\mathrm{e}, \mathrm{g}} \\
40(37-58)^{\mathrm{e}, \mathrm{g}}\end{array}$ \\
\hline
\end{tabular}

Data in medians (interquartile ranges). ${ }^{\mathrm{a}} V_{d}$, distribution volume; ${ }^{\mathrm{b}} k$, fractional removal constant; ${ }^{\mathrm{c}} \mathrm{MCR}$, metabolic clearance rate; ${ }^{\mathrm{d}} T R_{a}$, total rate of appearance; ${ }^{\mathrm{e}} p<0.05$ from non- obese healthy subjects; ${ }^{\mathrm{f}} p<0.05$ from obese patients with Type II diabetes; ${ }^{\mathrm{g}} p<0.05$ from baseline significant in obese Type II diabetic patients. At this high rate of insulin infusion plasma triglyceride was lower in non-obese healthy subjects than in the other groups.

Baseline plasma NEFA were lower in non-obese healthy subjects than in obese Type II diabetic patients (Table 3). At the first insulin infusion step plasma NEFA were lower in non-obese healthy subjects than in both diabetic groups, whereas after the second insulin infusion step plasma NEFA were lower in non-obese healthy than in obese patients with
Type II diabetes. The distribution volume $\left(V_{d}\right)$ was not different between the groups at baseline and during hyperinsulinaemia (Table 3). In the separate groups, the changes in $V_{d}$ during hyperinsulinaemia did not reach statistical significance in most situations. In the combined groups, the increase in $V_{d}$ was significant during each insulin infusion step $(p<0.05$ from baseline, data not shown). The fractional disappearance rate $(k)$ was similar in the groups at baseline and rose in all groups during hyperinsulinaemia (Table 3). As a result, the metabolic clearance rate, 


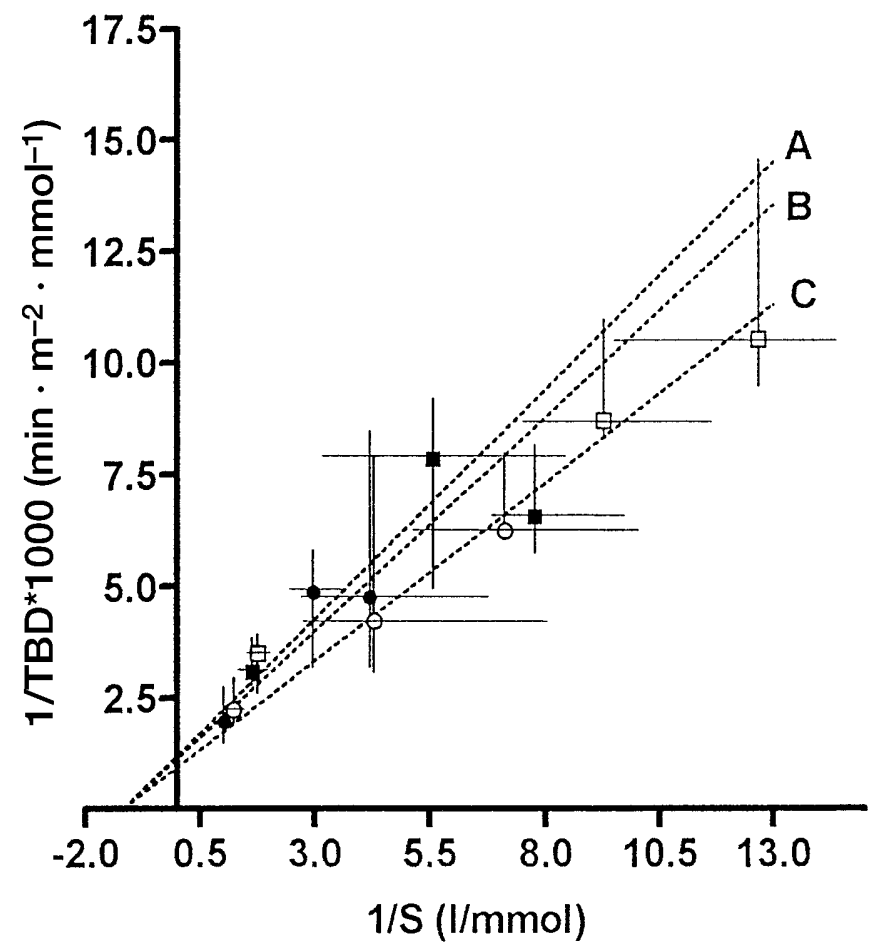

Fig. 1. Lineweaver-Burk plots showing the relation between 1/S (S denotes the apparent NEFA concentration at the site of transport) and 1/TBD (TBD denotes the whole body total NEFA disposal) at baseline (line A), during insulin infused at $30 \mathrm{mU} \cdot \mathrm{kg}^{-1} \cdot \mathrm{h}^{-1}$ (line B) and during insulin infused at $150 \mathrm{mU} \cdot \mathrm{kg}^{-1} \cdot \mathrm{h}^{-1}$ (line C). The values of $K_{m}$ and $V_{m}$ were obtained by multiple regression analysis (see text). The intercepts between the regression lines and the $\mathrm{x}$-axis represent $-1 / K_{m}$, where $K_{m}=850 \mu \mathrm{mol} / \mathrm{l}$. The intercepts between the regression lines and the y-axis represent $1 / V_{m}$, where $V_{m}=829,889$ and $1065 \mu \mathrm{mol} \cdot \mathrm{min}^{-1} \cdot \mathrm{m}^{-2}$ for lines A, B and C, respectively. $\square$, $\square, \bigcirc$, represent median (interquartile range) values in non-obese and obese healthy subjects and in non-obese and obese patients with Type II diabetes, respectively

$\operatorname{MCR}\left(=k \cdot V_{d}\right)$, which was not different between the groups at baseline, increased in all groups during hyperinsulinaemia (Table 3 ). At baseline, $T R_{a}$ tended to be higher in obese Type II diabetic patients than in non-obese healthy subjects $(p<0.10$, Table 3$)$. The $T R_{a}$ decreased greatly during hyperinsulinaemia in all groups. At the first insulin step $T R_{a}$ was significantly lower in non-obese healthy subjects than in the other groups. At the second insulin infusion step $T R_{a}$ remained lower in non-obese healthy than in obese subjects with Type II diabetes (Table 3 ).

Based on equation 3, multiple regression analysis with $1 / \mathrm{MCR}$ as a dependent variable resulted in the following formula: $1 / \mathrm{MCR}=\left(1.97+2.32 \cdot 10^{-3} \cdot\right.$ plasma NEFA $+2.10 \cdot 10^{-3} \cdot \mathrm{LPL} \cdot$ plasma triglyceride $) /$ $V_{d}$ (120 data sets, multiple $r=0.899$ with $p$ values for the three coefficients of $<0.01,<0.001$ and 0.041 , respectively). Applying the coefficients of this formula, $K_{m}$ was calculated to be $(1.97 / 2.32) \cdot 10^{3} \mu \mathrm{mol} / \mathrm{l}=$ $850 \mu \mathrm{mol} / \mathrm{l}$ and $A$ was calculated to be (2.10/
$2.32) \cdot 10^{-3} 1 / \mathrm{U}=0.904 \mathrm{l} / \mathrm{U}$ in the 3 kinetic experiments. The $V_{m}$ was calculated as $(1 / 2.32) \cdot 10^{3} V_{d}$, resulting in values of 829,889 and $1065 \mu \mathrm{mol}$. $\min ^{-1} \cdot \mathrm{m}^{-2}$ in the basal situation and at low-dose and high-dose insulin infusion, respectively, using the averaged $V_{d}$ values of the 40 participants of 1.92, 2.06 and $2.47 \mathrm{l} \cdot \mathrm{min}^{-1} \cdot \mathrm{m}^{-2}$ at the three kinetic experiments. Multiple regression analysis did not show significant contributions of the diabetic state or obesity to the values of $V_{m}, K_{m}$ and $A$ ( $p>0.10$ for all). There was also no significant contribution of the plasma insulin concentration on any of these variables ( $p>0.10$ for all). In a separate model, LPL was substituted by HL. No influence of HL activity on 1/MCR was found $(p=0.89)$.

Using the calculated variables $K_{m}$ and $A$ and $V_{m}$ we approximated, for each subject, the actual NEFA concentration at the site of transport (S), the extraction coefficient (Ext), the rate of disposal of intravascularly released NEFA (TU), the rate of escape of intravascularly released NEFA (ESC), the net rate of tissue lipolysis (RL) and rate of whole-body total NEFA disposal (TBD). Figure 1 shows the Lineweaver-Burk plot of the linear relation between $1 / \mathrm{S}$ and 1/TBD for the three kinetic experiments using the variables from the multiple regression analysis. Also depicted are the median (interquartile range) values of $1 / \mathrm{S}$ and $1 / \mathrm{TBD}$ from each group during the experiments. Figure 2 shows the relations between plasma insulin and S, Ext, ESC and RL for each group. The $S$ declined in all groups with increasing plasma insulin (Fig. 2). At baseline, $\mathrm{S}$ was higher in obese patients with Type II diabetes than in non-obese and obese healthy subjects. At both insulin infusion steps, S was lower in the non-obese healthy subjects than in the other groups. Changes and differences in TBD paralleled those in S (data not shown). The Ext rose in all groups during hyperinsulinaemia (Fig. 2). At baseline, Ext was lower in obese patients with Type II diabetes than in non-obese and obese healthy subjects. At the low and high rate of insulin infusion, Ext was higher in non-obese healthy subjects than in the other groups. The ESC decreased in each group with increasing plasma insulin (Fig.2). At baseline and at the first insulin infusion step, ESC was higher in both groups with Type II diabetes than in nonobese healthy subjects. At the second insulin infusion step, ESC was higher in obese Type II diabetic patients than in non-obese healthy subjects. Thus, as suggested by Figure 2, both obesity and the diabetic state seemed to result in similar alterations in S, Ext and ESC in relation to the prevailing plasma insulin concentration. In obese Type II diabetic patients, these abnormalities seemed to be aggravated. The RL declined in all groups during hyperinsulinaemia (Fig. 2). In contrast to the three former variables, RL was, however, not different between the groups in any of the kinetic experiments. 

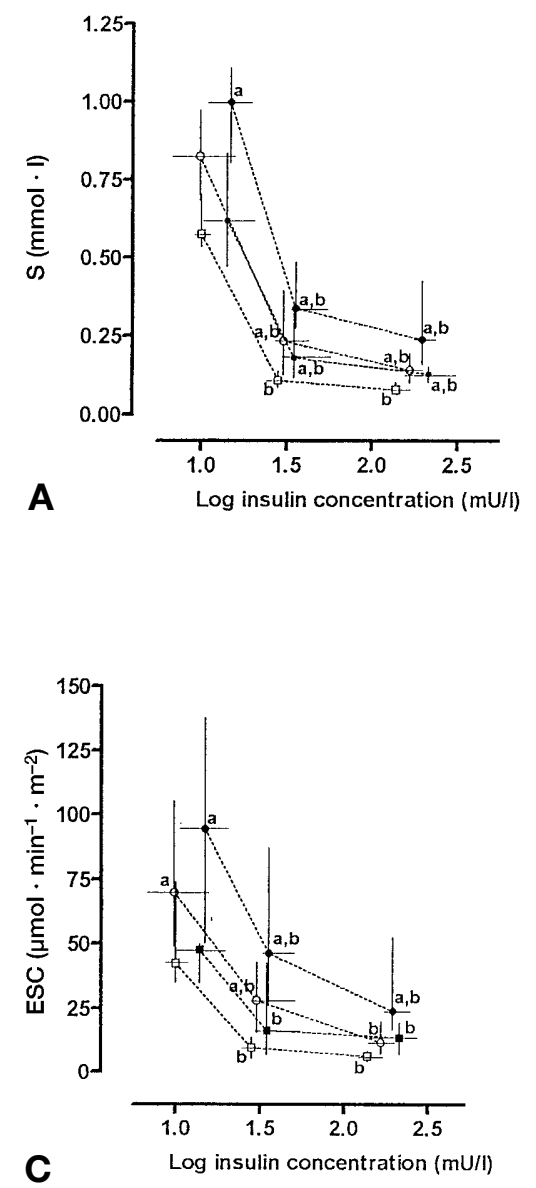

Fig. 2 A-D. Relations between plasma insulin and S, the apparent NEFA concentration at the site of transport (A), Ext, the extraction coefficient (B), ESC, the rate of escape of intravascularly released NEFA $(\mathbf{C})$ and $\mathrm{RL}$, the net rate of tissue lipolysis (D). $\square, \mathbf{Q}, \bigcirc$, $\bigcirc$ represent median (interquartile range) values in non-obese and obese healthy subjects and in non-obese and obese patients with Type II diabetes, respectively. ${ }^{\mathrm{a}} p<0.05$ from non-obese healthy subjects, ${ }^{\mathrm{b}} p<0.05$ from baseline

Multiple regression analysis was used to evaluate the influence of the glucose infusion rate, the diabetic state, obesity and the two levels of hyperinsulinaemia on the actual values of TBD and RL. In this analysis, the diabetic state, obesity and the two levels of hyperinsulinaemia were considered as categorical variables. The TBD was found to be negatively related to glucose infusion rate $(p=0.014)$ and was increased by both the diabetic state $(p=0.009)$ and obesity $(p=0.014$, multiple $r=0.542)$. In this model, the degree of hyperinsulinaemia did not contribute independenly $(p=0.98)$ to the actual TBD. The RL was only inversely related to the degree of hyperinsulinaemia $(p=0.011)$ without a significant influence of the glucose infusion rate $(p=0.786)$, the diabetic state $(p=0.135)$ and obesity $(p=0.93)$.
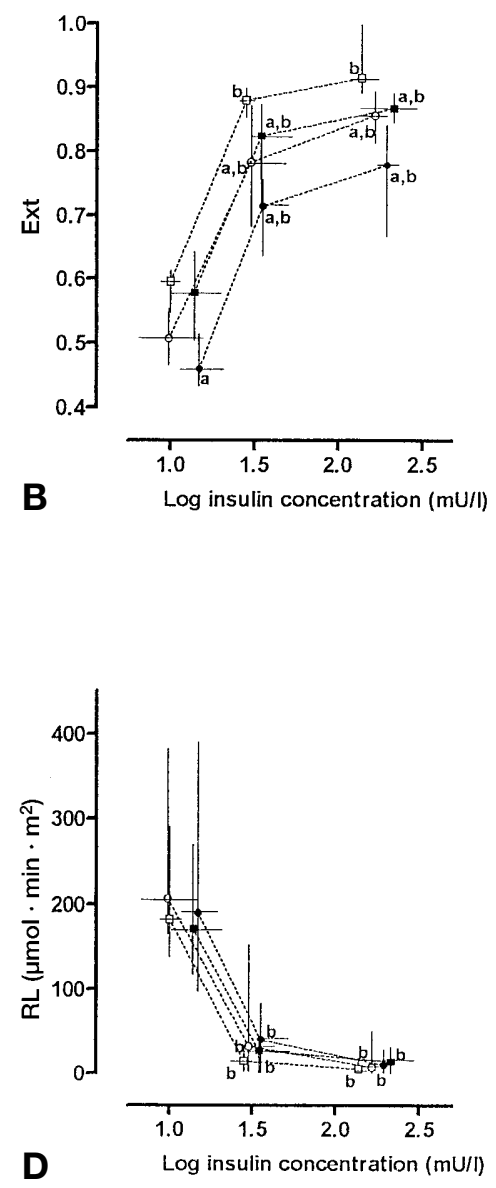

\section{Discussion}

As expected [13,14, 16, 34, 35], this study showed that the plasma NEFA concentration is increased in the fasting state and is less suppressible by insulin in obese Type II diabetic patients compared with nonobese healthy subjects. Using non-equilibrium tracer conditions, we found impaired suppression of the arterial plasma NEFA rate of appearance, $T R_{a}$, in obese subjects and patients with Type II diabetes at low-dose insulin infusion and also in obese patients with Type II diabetes at high-dose insulin infusion. This again seems to agree with previous data obtained by prolonged tracer infusion [13-16].

Total arterial plasma NEFA rate, as assessed in the present study, is composed of both the rate of appearance of NEFA derived from tissue stores and of NEFA appearing from intravascularly hydrolysed triglyceride that escape from tissue uptake [20-22]. The rate of appearance of NEFA, measured by prolonged tracer infusion, is, in contrast, considered to represent only their release from tissue stores [13-16, 36, 37]. This assumption holds true in those situations where the specific radioactivity of the fatty acids in circulating triglyceride equals that of circulating NEFA. Such conditions are met if the circulating pool of esterified fatty acids is completely formed by re-esterification of circulating NEFA. In the basal 
state this assumption is likely to be correct [38] but during hyperinsulinaemia and abundant supply of glucose, de novo synthesis of fatty acids contributes to a relevant extent to hepatic triglyceride production [38]. Hence, under such circumstances, the rate of appearance of NEFA, assessed by prolonged tracer infusion, is bound to measure intravascularly released NEFA that escape from tissue uptake together with NEFA released from tissue stores. Therefore, impaired insulin-induced suppression of the rate of appearance of NEFA so measured does not necessarily imply an impaired antilipolytic action of insulin, but could also be attributable to an enhanced escape from direct uptake of intravascularly released NEFA.

Unlike measurement of NEFA kinetics during equilibrium tracer conditions, the non-equilibrium method enables measurement of factors that constitute MCR, i.e. the distribution volume, $V_{d}$ and the fractional removal constant, $k$. In the basal state, $V_{d}$ was approximately $1.9 \mathrm{l} / \mathrm{m}^{2}$. Regarding $V_{d}$ in terms of a volume flow and assuming a haematocrit of $0.4, V_{d}$ would represent a blood flow of about 3.2 $1 \cdot \min ^{-1} \cdot \mathrm{m}^{-2}$, a value similar to the cardiac output. When the data from the groups were combined, $V_{d}$ rose with increasing plasma insulin, in keeping with the positive inotropic effect of insulin and the insulin-induced increase in perfusion of tissues like muscle and adipose tissue as shown in some studies [17, 39]. Using actual values of $V_{d}$, we were able to approximate both components of $T R_{a}$, i.e. the net rate of tissue lipolysis, RL and the rate of intravascular escape from tissue uptake, ESC by application of a model of whole-body total NEFA disposal, TBD. The model presented here is based on several assumptions. Firstly, as shown in vitro, transmembrane NEFA transport was considered to be a facilited diffusion process [30-33] that follows Michaelis-Menten kinetics. Indeed, several protein factors have been identified that facilitate long-chain fatty acid transport across cell membranes [33, 40, 41]. It can be argued that the low unbound NEFA concentrations that are likely to be present under our experimental conditions make simple diffusion of NEFA across cell membranes of minor importance in NEFA transmembrane transport [30, 33]. It should be noted, however, that the physiology of NEFA transmembrane transport is still under debate [33, 41, 42].With the assumption that transmembrane NEFA transport follows Michaelis-Menten kinetics, TBD would then follow Michaelis-Menten kinetics as well, in analogy with such kinetics of whole-body glucose disposal $[43,44]$. In our model, the action of lipases on intravascular triglyceride metabolism and, hence, on NEFA kinetics was crucial. No effect of HL activity on NEFA kinetics could be shown and this lipase was, therefore, not considered further. We assumed that the rate of intravascular triglyceride hydrolysis is proportional to LPL activity, the arterial plasma triglyceride concentration and the plasma flow (PF) in tissues capable of hydrolysing triglyceride. Lipoprotein lipase activity was measured in post-heparin plasma shortly before the experiments because the biological effect of the low LPL activity in native pre-heparin plasma is unclear. Because there was no independent contribution of the plasma insulin concentration to the reaction rate constant of intravascular triglyceride hydrolysis $(A)$, the total amount of active LPL (corresponding to $A \cdot \mathrm{LPL}$ ) was considered to remain unaltered during the experiments, as suggested previously [17]. In healthy subjects, LPL activity has been shown to increase in adipose tissue [45, 46] and to decrease in skeletal muscle [46] in response to insulin. In another study, the increase in native plasma LPL activity after insulin was not different from that after saline infusion [47]. Furthermore, we assumed that plasma triglycerides were completely hydrolysed by LPL $[18,48]$ and that the changes in the composition of triglyceride-rich lipoproteins occurring after insulin infusion $[49,50]$ were not so prominent that the use of the plasma triglyceride concentration as the substrate concentration for LPL action became inappropriate. Finally, it was assumed that intravascular triglyceride hydrolysis was proportional to tissue plasma flow, as witnessed by the virtually unchanged arterial-venous plasma triglyceride difference in adipose tissue, despite a large increase in blood flow, as evoked by adrenalin [48].

Applying multiple regression analysis, it was shown that the model sufficiently described the NEFA concentration at the site of transport at half maximum disposal rate, $K_{m}$, and the maximum transport capacity, $V_{m}$ (expressed per body surface area). These characteristics of the NEFA transport system were unaffected by the presence of Type II diabetes and obesity. The maximum transport capacity $\left(V_{m}\right)$ rose during hyperinsulinaemia in proportion with the increase in $V_{d}$. Moreover, the distribution of blood supply to the various organs involved in NEFA metabolism seemed to remain similar during hyperinsulinaemia because both $V_{m}\left(B \cdot V_{d}\right)$ and $\mathrm{PF}$ $\left(B \cdot V_{d} / K_{m}\right)$ kept a constant relation to $V_{d}$. This was expected because changes in cardiac output and tissue perfusion, particularly muscle, are highly correlated under hyperinsulinaemic conditions [39]. As insulin infusion evoked a rise in $V_{d}$, the rate of intravascular triglyceride hydrolysis $\left(A \cdot \mathrm{LPL} \cdot B \cdot V_{d}\right)$ increased during hyperinsulinaemia despite a lack of change in the reaction rate constant of intravascular triglyceride hydrolysis, $A$.

Using the model-derived constants, the coefficient of extraction of NEFA across tissues, Ext, as well as the two components of $T R_{a}, \mathrm{RL}$ and ESC, could be approximated for the individual subjects under the three experimental conditions. The Ext increased during hyperinsulinaemia, but did not reach 1.0 in any group. Accordingly, retention of NEFA in adi- 
pose tissue is incomplete after a high fat meal combined with a hyperinsulinaemic clamp $[17,18]$. The methodology used in our study assesses only that part of tissue lipolysis that results in actual NEFA release. Under the present experimental conditions, with oral glucose lowering agents being withheld only during the experiments and evaluating adequately controlled Type II diabetic patients, RL (expressed per body surface area) was not different between the groups in the basal state and after hyperinsulinaemia. This proves that in this situation, abnormalities in the antilipolytic response to insulin (judged by RL) do not contribute to an important extent to the impaired suppression of $T R_{a}$ in Type II diabetic patients and in obese subjects at a low rate of insulin infusion and in obese Type II diabetic patients at a high rate of insulin infusion. Instead, our study not only confirmed a considerable contribution of ESC to $T R_{a}$ in non-diabetic subjects in the postabsorptive state [17, 22] but also showed an enhanced ESC at baseline and at a low rate of insulin infusion in both groups with Type II diabetes and also at a high rate of insulin infusion in obese Type II diabetic patients. We suggest that this enhanced escape is a consequence of the increased NEFA concentration at the site of transport, S, due to enhanced intravascular triglyceride hydrolysis. This increased release of NEFA is based solely on the higher plasma triglyceride concentration associated with Type II diabetes and obesity because LPL activity and PF were similar in all groups. An increased NEFA concentration at the site of transport will lead to a higher TBD. Consequently, TBD was positively related to the diabetic state and obesity during hyperinsulinaemia.

It is plausible that these abnormalities in NEFA kinetics in Type II diabetes and obesity result from altered regulation of triglyceride-rich lipoprotein secretion in response to insulin. The insulin-induced decrease in hepatic apo B secretion has been shown to be impaired in Type II diabetes [51], although this has not always been observed [52]. In obesity, the decrease in apo B secretion and in plasma triglyceride after insulin is impaired as well [49]. In that report, the lowering of hepatic VLDL triglyceride secretion was unaltered but the insulin dose was approximately threefold lower than that in our study [49]. Because the plasma NEFA concentration is an important determinant of hepatic triglyceride synthesis $[1,53]$, we postulate that an impaired suppression of hepatic triglyceride secretion by insulin in Type II diabetes and obesity will lead to an enhanced $T R_{a}$ and, hence, to a futile NEFA cycle.

The negative relation between NEFA and glucose metabolism has been widely reported [2-7, 13-16, $54,55]$. Our study showed a negative interrelation between the glucose infusion rate during hyperinsulinaemia and TBD, although the absence of hepatic glucose production measurement does not allow us to explain the precise relation between NEFA kinetics and peripheral insulin sensitivity of glucose metabolism. No independent effect of hyperinsulinaemia on actual TBD was found. Others have shown that the decrease in NEFA oxidation during hyperinsulinaemia [56] is a consequence of lowered NEFA concentrations rather than a direct effect of insulin [14]. Of note, the present experiments showed that RL was unrelated to glucose infusion rate during hyperinsulinaemia, which suggests with the aforementioned restrictions that there was no direct interrelation between net rate of tissue lipolysis and insulin sensitivity of glucose metabolism.

This study suggests that the enhanced $T R_{a}$ during hyperinsulinaemia in adequately controlled patients with Type II diabetes and obese subjects does not result from a defect in suppressibility of tissue lipolysis but from escape of NEFA uptake after intravascular triglyceride hydrolysis. This, in turn, is likely to be attributable to higher plasma triglyceride concentrations which could be related to impaired lowering of triglyceride secretion by insulin. Such a defect could represent one of the main components of the complex abnormalities in overall lipid handling in these conditions, which bare an increased risk of cardiovascular disease.

Acknowledgements. This study is supported by grant 94-130 from the Dutch Diabetes Foundation. Dr H. Jansen, Department of Biochemistry, Erasmus University Rotterdam, The Netherlands, did the LPL and HL assays. Drs A. van Tol and W.D Reitsma are acknowledged for critical manuscript reading. The technical assistance of W. de Jonge and J. J. Zwaagstra is greatly appreciated.

\section{References}

1. Coppack SW, Jensen MD, Miles JM (1994) In vivo regulation of lipolysis in humans. J Lipid Res 35: 177-193

2. Randle PJ, Priestman DA, Mistry S, Halsall H (1994) Mechanisms modifying glucose oxidation in diabetes mellitus. Diabetologia 37[Suppl 2]: 155-161

3. Roden M, Price TB, Perseghin G et al. (1996) Mechanism of free fatty acid-induced insulin resistance in humans. J Clin Invest 97: 2859-2865

4. Saloranta C, Koivisto V, Widén E et al. (1993) Contribution of muscle and liver to glucose-fatty acid cycle in humans. Am J Physiol 264:E599-E605

5. Nurjhan N, Consoli A, Gerich J (1992) Increased lipolysis and its consequences on gluconeogenesis in non-insulin-dependent diabetes mellitus. J Clin Invest 89: 169-175

6. Frayn KN, Coppack SW (1992) Insulin resistance, adipose tissue and coronary heart disease. Clin Sci (Colch) 82: $1-8$

7. Björntorp P (1994) Fatty acids, hyperinsulinemia and insulin resistance: which comes first? Curr Opin Lipidol 5: 166-174

8. Arner P, Bolinder J, Engfeldt P, Östman J (1981) The antilipolytic effect of insulin in human adipose tissue in obesity, diabetes mellitus, hyperinsulinemia, and starvation. Metabolism 301: 753-760 
9. Bolinder J, Östman J, Arner P (1982) Postreceptor defects causing insulin resistance in normoinsulinemic non-insulin-dependent diabetes mellitus. Diabetes 31: 911-916

10. Löhnroth P, Digirolamo M, Krothiewski M, Smith U (1993) Insulin binding and responsiveness in fat cells from patients with reduced glucose tolerance and type II diabetes. Diabetes 32: 748-754

11. Pedersen O, Hjollund E, Sorensen NS (1982) Insulin receptor binding and insulin action in human fat cells: effects of obesity and fasting. Metabolism 31: 884-895

12. Yki-Järvinen H, Kubo K, Zawadzki J et al. (1987) Dissociation of in vitro sensitivities of glucose transport and antilipolysis to insulin in NIDDM. Am J Physiol 253: E300-E304

13. Groop LC, Bonadonna RC, DelPrato S et al. (1989) Glucose and free fatty acid metabolism in non-insulin dependent diabetes mellitus. Evidence for multiple sites of insulin resistance. J Clin Invest 84: 205-213

14. Groop LC, Saloranta C, Shank M, Bonadonna RC, Ferrannini E, DeFronzo RA (1991) The role of free fatty acid metabolism in the pathogenesis of insulin resistance in obesity and noninsulin-dependent diabetes mellitus. J Clin Endocrinol Metab 72: 96-107

15. Groop LC, Bonadonna RC, Simonson DL, Petrides AS, Shank M, DeFronzo RA (1992) Effect of insulin on oxidative and nonoxidative pathways of free fatty acid metabolism in human obesity. Am J Physiol 263:E79-E84

16. DelPrato S, Enzi G, Vigili de Kreuzenberg S et al. (1990) Insulin regulation of glucose and lipid metabolism in massive obesity. Diabetologia 33: 228-236

17. Frayn KN, Shadid S, Hamlani R et al. (1994) Regulation of fatty acid movement in adipose tissue in the postabsorptive-to-postprandial transition. Am $\mathrm{J}$ Physiol 266: E308-E317

18. Frayn KN, Coppack SW, Fielding BA, Humphreys SM (1995) Coordinated regulation of hormone-sensitive lipase and lipoprotein lipase in human adipose tissue in vivo: implications for the control of fat storage and fat mobilization. Adv Enzyme Regul 35: 163-178

19. Hultin M, Savonen R, Olivecrona T (1996) Chylomicron metabolism in rats: lipolysis, recirculation of triglyceridederived fatty acids in plasma FFA, and fate of core lipids as analyzed by compartmental modelling. J Lipid Res 37: 1022-1036

20. Birkenhäger JC, Tjabbes T (1969) Turnover rate of plasma FFA and rate of esterification of plasma triglycerides in obese humans before and after weight reduction. Metabolism 18: 18-32

21. Scow RO (1977) Metabolism of chylomicrons in perfused adipose and mammary tissue of the rat. Fed Proc 36: 182-185

22. Riemens SC, Dullaart RP, Franssen EJ, Piers DA, Reitsma WD, Sluiter WJ (1998) Measurement of free fatty acid kinetics during non-equilibrium tracer conditions in man: implications for the estimation of the rate of appearance of free fatty acids. Eur J Clin Invest 28: 108-114

23. National Diabetes Data Group (1979) Classification and diagnosis of diabetes mellitus and other categories of glucose intolerance. Diabetes 28: 1039-1057

24. Lukaski HC, Johnson PE, Bolonchuk WW, Lykken GI (1985) Assesment of fat-free mass using bioelectrical impedance measurements of the human body. Am J Clin Nutr 41: 810-817

25. Riemens SC, Van Tol A, Sluiter WJ, Dullaart RP (1998) Plasma phospholipid transfer protein activity is related to insulin resistance and altered free fatty acid and triglycerides: impaired acute lowering by insulin in obese Type II diabetic patients. Diabetologia 41: 929-934
26. Jensen MD, Heiling VJ (1991) Heated hand vein blood is satisfactory for measurements during free fatty acid kinetic studies. Metabolism 40: 406-409

27. Jansen H, Hop W, Van Tol A, Bruschke AV, Birkenhäger JC (1994) Hepatic lipase and lipoprotein lipase are not major determinants of the low density lipoprotein subclass pattern in human subjects with coronary heart disease. Atherosclerosis 107: 45-54

28. Demacker PN, Hijmans AG, Vos-Janssen HE, Van't Laar A, Jansen AP (1980) A study of the use of polyethylene glycol in estimating cholesterol in high-density lipoprotein. Clin Chem 26: 1775-1779

29. Eaton RP, Berman M, Steinberg D (1969) Kinetic studies of plasma free fatty acid and triglyceride metabolism in man. J Clin Invest 48: 1560-1579

30. Abumrad NA, Perkins RC, Park JH, Park CR (1981) Mechanism of long chain fatty acid permeation in the isolated adipocyte. J Biol Chem 256: 9183-9191

31. Abumrad NA, Perry PR, Whitesell RR (1986) Insulin antagonizes epinephrine activation of the membrane transport of fatty acids. Potential site for hormonal suppression of lipid mobilization. J Biol Chem 261: 2999-3001

32. Stremmel W (1988) Fatty acid uptake by isolated rat heart myocytes represents a carrier-mediated transport process. J Clin Invest 81: 844-852

33. Abumrad N, Harmon C, Ibrahimi A (1998) Membrane transport of long-chain fatty acids: evidence for a facilitated process. J Lipid Res 39: 2309-2318

34. Chen YD, Golay A, Swislocki AL, Reaven GM (1987) Resistance to insulin suppression of plasma free fatty acid concentrations and insulin stimulation of glucose uptake in noninsulin-dependent diabetes mellitus. J Clin Endocrinol Metab 64: 17-21

35. Skowronski R, Hollenbeck CB, Varasteh BB, Chen YD, Reaven GM (1991) Regulation of non-esterified fatty acid and glycerol concentration by insulin in normal individuals and patients with type 2 diabetes. Diabet Med 8: 330-333

36. Jensen MD, Caruso M, Heiling V, Miles JM (1989) Insulin regulation of lipolysis in nondiabetic and IDDM subjects. Diabetes 38: 1595-1601

37. Campbell PJ, Carlson MG, Hill JO, Nurjhan N (1992) Regulation of free fatty acid metabolism by insulin in humans: role of lipolysis and reesterification. Am $\mathrm{J}$ Physiol 263:E1063-E1069

38. Aarsland A, Chinkes D, Wolfe RR (1996) Contributions of de novo synthesis of fatty acids to total VLDL-triglyceride secretion during prolonged hyperglycemia/hyperinsulinemia in normal man. J Clin Invest 98: 2008-2017

39. Baron AD (1993) Cardiovascular actions of insulin in humans. Implications for insulin sensitivity and vascular tone. Baillières Clin Endocrinol Metab 7: 961-987

40. Schaffer JE, Lodish HF (1994) Expression cloning and characterization of a novel adipocyte long chain fatty acid transport protein. Cell 79: 427-436

41. Bonen A, Dyck DJ, Luiken JJ (1998) Skeletal muscle fatty acid transport and transporters. Adv Exp Med Biol 441: 193-205

42. Hamilton JA (1998) Fatty acid transport: difficult or easy? J Lipid Res 39: 467-481

43. Gottesman I, Mandarino L, Verdonk C, Rizza R, Gerich J (1982) Insulin increases the maximum velocity for glucose uptake without altering the Michaelis constant in man. Evidence that insulin increases glucose uptake merely by providing additional transport sites. J Clin Invest 70: 1310-1314

44. Yki-Järvinen H, Young AA, Lamkin C, Foley JE (1987) Kinetics of glucose disposal in whole body and across the forearm in man. J Clin Invest 79: 1713-1719 
45. Yki-Järvinen H, Taskinen MR, Koivisto VA, Nikkilä EA (1984) Response of adipose tissue lipoprotein lipase activity and serum lipoproteins to acute hyperinsulinaemia in man. Diabetologia 27: 364-369

46. Farese RV, Yost TJ, Eckel RH (1991) Tissue-specific regulation of lipoprotein lipase activity by insulin/glucose in normal-weight humans. Metabolism 40: 214-216

47. Malmström R, Packard CJ, Watson TD et al. (1997) Metabolic basis of hypotriglyceridemic effects of insulin in normal men. Arterioscler Thromb Vasc Biol 17: 1454-1464

48. Samra JS, Simpson EJ, Clark ML et al. (1996) Effects of epinephrine infusion on adipose tissue: interactions between blood flow and lipid metabolism. Am J Physiol 271: E834-E839

49. Lewis GF, Uffelman KD, Szeto LW, Steiner G (1993) Effects of acute hyperinsulinemia on VLDL triglyceride and VLDL apo B production in normal weight and obese individuals. Diabetes 42: 833-842

50. Malmström R, Packard CJ, Caslake M et al. (1998) Effects of insulin and acipimox on VLDL1 and VLDL2 apolipoprotein $\mathrm{B}$ production in normal subjects. Diabetes 47: 779-787

51. Malmström R, Packard CJ, Caslake M et al. (1997) Defective regulation of triglyceride metabolism by insulin in the liver in NIDDM. Diabetologia 40: 454-462
52. Cummings MH, Watts GF, Umpleby M et al. (1995) Acute hyperinsulinemia decreases the hepatic secretion of verylow-density lipoprotein B-in NIDDM. Diabetes 44: 1059-1065

53. Lewis GF, Uffelman KD, Szeto LW, Weller B, Steiner G (1995) Interaction between free fatty acids and insulin in the acute control of very low density lipoprotein production in humans. J Clin Invest 95: 158-166

54. Vaag A, Skött P, Damsbo P, Gall MA, Richter EA, BeckNielsen H (1991) Effect of the antilipolytic nicotinic acid analogue acipimox on whole-body and skeletal muscle glucose metabolism in patients with non-insulin-dependent diabetes mellitus. J Clin Invest 88: 1282-1290

55. Fulcher GR, Walker M, Catalano C, Agius L, Alberti KGMM (1992) Metabolic effects of suppression of nonesterified fatty acid levels with acipimox in obese NIDDM subjects. Diabetes 41: 1400-1408

56. Bonadonna RC, Groop LC, Zych K, Shank M, DeFronzo RA (1990) Dose-dependent effect of insulin on plasma free fatty acid turnover and oxidation in humans. Am J Physiol 259: E736-E750 